\title{
Tales of the Unknown and Entanglement: An Early Career Researcher's Qualitative Immersive Fieldwork Experience in a Nursing-Hospital Context
}

\author{
Noof Aldaheri, Gustavo Guzman and Heather Stewart \\ Griffith University, Gold Coast, Australia \\ Noof.aldaheri@griffithuni.edu.au \\ g.guzman@griffith.edu.au \\ h.stewart@griffith.edu.au \\ DOI: 10.34190/RM.19.046
}

\begin{abstract}
The purpose of this paper is to explore and reflect on the fieldwork dilemmas of an early career researcher in conducting management qualitative research in a nursing-hospital context. The complexity of fieldwork dilemmas, especially issues of nursing-hospital contextual factors and identities, as well as how they were negotiated to gain and maintain fieldwork entry and information access is also discussed. Drawing on the most uncertain fieldwork moments that are derived from 22,936 words of field notes collected during a prolonged period of fieldwork, as well as a researcher's retrospective sense of fieldwork experience, author will describe and analyse fieldwork dilemmas. Through employing the lens of reflexivity and the notion of "activating the hyphen" between nursing-hospital insiders, research informants and the researcher, the most uncertain fieldwork moments and their criticality in gaining and maintaining fieldwork entry and information access are selected and categorized into three interrelated tales: confronting official layers of gatekeepers, confronting hesitancy and finding insider roles. Fieldwork dilemmas of the management qualitative research in a nursinghospital context mainly arise from complex combinations of nursing-hospital contextual factors and multiple identity boundaries and perceptions between the researched nursing-hospital settings, nurse informants and the researcher. In addition to the multiple identity boundaries and perceptions, some constraints and opportunities were experienced with respect to fieldwork entry and information access. The fieldwork accounts provided explore and reflect upon the complicity of fieldwork dilemmas when conducting management qualitative research in a nursing-hospital context, specifically when fundamental differences between the researcher and research informants take place. The practical means described to negotiate contextual factors and multiple identity perceptions will be valuable to early career researchers, especially those preparing for field experiences in nursing-hospital contexts for the first time.
\end{abstract}

Keywords: Management research, fieldwork, nursing-hospital context, contextual factors, identities, early career researcher

\section{Introduction}

Numerous prominent management contributions propose embracing qualitative research approaches to make a shift toward context-sensitive research (Johns, 2018). It is argued that understanding the contextual conditions helps to develop powerful theories (Child \& Marinova, 2014), explain the current status quo of inconsistencies in the research findings (Sergeeva \& Aneeva 2016), and enhance the validity of qualitative research findings (Rousseau \& Fried, 2001). The contextualisation of research can take place in several stages of the research process ranging from site selection, question formulation, interpretation and reporting.

Context is highly invisible, and thus, it requires greater attention to the research setting (Rousseau \& Fried, 2001). Qualitative immersive fieldwork is an appropriate method to contextualise research. This is because a researcher's fieldwork experience itself can extensively uncover the contextual conditions under which data are generated.

Qualitative fieldwork as an instrument with which a researcher immerses themselves in a new social context to understand the researched context is full of real life uncertainties and contingencies (Cole, 2013).

Negotiation of strong gatekeeping (Grant, 2017), psychic discomfort (Chong, 2008) and theoretical and methodological orientation changes (Cole, 2013) are some examples of fieldwork dilemmas. Fieldwork dilemmas significantly emerge from contextual factors (Høyland, Hollund, \& Olsen, 2015) and the largely blurred boundaries of identities that take place between a researcher and a researched context (Sherif, 2001).

There are few published accounts that reflect upon the use of immersive fieldwork methods in nursinghospital spaces by non-nurses ethnographers, with Sandars (2009) and Davis (2000) being two notable 


\section{Noof Aldaheri, Gustavo Guzman and Heather Stewart}

exceptions. However, these two authors predominantly used self-reflection as a lens through which to describe the encountered fieldwork dilemmas and their influence on information access. Emphasising merely on the researcher's experience and emotional status in the ethnographic accounts has been criticised as enhancing the researcher's self-indulgence, exhibitionism, and even narcissism (Chesney, 2001; Coffey, 1999).

Alternatively, the notion of "working the hyphen", initially conceptualised by Fine (1994b), developed to recognise the mutual influence of a researcher and researched identities in the process of knowledge constructions is an appropriate reflective lens through which to create more balanced accounts that take into consideration the relationship between researchers and the researched.

"Working the hyphen", according to Fine, implies that "researchers probe how we are in relation with the contexts we study and with our informants, understanding that we are all multiple in those relations". He further elaborated: "I mean to invite researchers to see how these 'relations between' that get us 'better' data, limit what we feel free to say" (Fine, 1994b, p. 72). Cunliffe and Karunanayake (2013) developed Fine's notion to introduce potential hyphen spaces that are deeply implicated and reciprocally influential in relationships between researchers and the researched. These hyphen spaces, which are determined and reflected upon by the second author's "fieldwork experience" entail insiderness-outsiderness, represented in the degree of a researcher being indigenous to the community being studied and similarities-differences in terms of the positionalities between a researcher and the research informants. According to Humphrey (2007), activating the hyphen through social interactions and conversations between a researcher and the research informants can improve a researcher's possibilities of surviving and thriving in intricate spaces.

The purpose of this paper is to explore and reflect on the fieldwork dilemmas of an early career researcher in nursing-hospital context, in particular, the complexity of fieldwork dilemmas especially issues of nursinghospital contextual factors and identities as well as how they were negotiated to gain and maintain fieldwork entry and information access. This work draws on the most uncertain fieldwork moments derived from 22,936 words of field notes collected during a prolonged fieldwork period as well as a researcher's retrospective sense of fieldwork experience in order to describe and analyse fieldwork dilemmas. Through employing the lens of reflexivity and the notion of "activating the hyphen" between nursing-hospital insiders, research informants and the researcher, the most uncertain fieldwork moments and their criticality in gaining and maintaining fieldwork entry and information access are selected and categorized into three interrelated tales.

I begin by setting the empirical context for my qualitative management fieldwork, followed by a discussion of illustrative tales that capture the most uncertain fieldwork moments including confronting official gatekeepers, confronting hesitancy and finding an insider role. I conclude by highlighting some methodological and practical implications.

\section{Empirical research context}

The presented tales in this paper originate from qualitative management fieldwork to gather empirical data for my doctoral thesis research. It explored my research aims to profoundly uncover how the phenomena of cross-cultural knowledge sharing between senior expatriate and host-country national nurses occur, and how they shape and are shaped by their organisational contextual conditions. My fieldwork was based in a Saudi Arabian public university hospital in three non-acute wards, namely the Male Surgical, Obstetrics and Gynaecology wards, for a six-month period (January 2018-Jun 2018). This fieldwork involved the primary observation of the selected hospital wards' physical features and the daily routine and activities of the nurses.

It also involved observing nursing collective practices such as medication administration, shift handover, documentation, orientation program and training workshops, in addition to reviewing HR documents and intensive semi-structured interviews.

\section{Tale 1: Confronting official layers of gatekeepers}

Negotiating qualitative fieldwork access is time-consuming and a continual process (Feldman, Bell \& Berger, 2003; Tracy, 2013), particularly if the researcher is not a member of the setting being researched (Tracy, 2013).

Although fieldwork accounts that provide extended details and insights into the laborious negotiation process of obtaining access to nursing-hospital research sites are scarce (Høyland et al., 2015), some nursing-hospital 


\section{Noof Aldaheri, Gustavo Guzman and Heather Stewart}

ethnographic researchers recognise that gaining access to nursing-hospital sites is a nonlinear process (Moore \& Savage, 2002; Toffoli \& Rudge, 2006). Thus, since starting my doctoral thesis research in the area of crosscultural knowledge sharing practices in 2016, I had begun a series of attempts to secure high-quality access with limited restrictions in the Saudi Arabian healthcare organisations that match a set of established criteria.

The difficulties associated with obtaining accessibility for qualitative fieldworks from healthcare organisations, particularly hospitals, are recognised in the literature (Høyland, Hollund \& Olsen, 2015; Long, Hunter \& van der Geest, 2008). One obvious explanation for such difficulties is represented by the concerns over patient privacy; another explanation is closely related to the defensiveness of hospital authorities and their scepticism and hesitation in permitting entry for researchers to closely observe their workplace (van der Geest \& Finkler, 2004).

Though a Saudi native, gaining access to a healthcare organisation in my homeland as a researcher was much more arduous than I initially anticipated. The results of my several unsuccessful access attempts clearly unveiled the fact that additional obstacles surround research fall outside the clinical research arena. For example, I received rejection responses that described my research proposal as "Beyond the hospital's Research Agendas" or "Unconventional Research". Two sets of realities can be drawn based on that. First, the value of management research does not seem to be appreciated in nursing-hospital settings. Second, the lack of familiarity with ethnographies and immersive fieldwork methods might have evoked scepticism, as these hospitals seem to merely rely on experimental and statistical research methods to address clinical issues.

Gaining access to nursing-hospital sites depends heavily on the researcher's capacities to seek alternative paths in order to negotiate strong gatekeeping (Abdulrehman, 2017). Therefore, after several unsuccessful attempts to gain direct access to hospitals, I realised that without insider connections and support from within a hospital, it would be difficult to accomplish my research objectives. This thought was underpinned by what prior nurses ethnographers suggest about the significant need for early identification and establishing contact with key insider individuals such as mangers or supervisors who have the knowledge and experiences that enable them to realise the potential value of a research proposal and assist in suggesting an appropriate route to seek and proceed with access endeavour (Høyland et al., 2015). In this process of attempting to gain entre, I engaged my family members and friends who have close contact with hospital insiders. Ultimately, I obtained some oral offers and promises to facilitate my research activities, but I had not been helped or guided to precede ethics and official permission. Therefore, I decided to forego these oral offers and continue looking for alternative official trajectories. I considered seeking support from nursing professors who are affiliated with universities' hospitals. Thus, I sent numerous formal emails, which eventually yielded support from a nursing professor, based at a Saudi Arabian university who was convinced by the values of my research. She was also willing to close a partnership as a local supervisor in order to share knowledge of the common access procedures for the university hospital, which involved assistant in fulfilment of the ethics requirements and seeking ethics approval from the University hospital ethical committee.

I spent substantial time completing what could be described as highly fixed ethical applications and requirements that are primarily tailored to accommodate clinical experiments, quantitative and interventionist research designs. Specific details regarding interview questions, the number of the intended research informants, informed consent procedures, research statistical analysis, research clinical objectives and outcomes were required to be supplied and presented at the inception which is inconsistent with the principles of qualitative management research and ethnographic fieldwork where researchers gradually develop research instruments and questions as their research proceeds. Likewise, several nursing-hospital ethnographic researchers (Allbutt \& Masters, 2010; Smith, 2008) acknowledge the difficulty of reconciliation of the rigid ethical applications and requirements of healthcare organisations with the elastic nature of qualitative research design. To bridge these existing gaps between the hospital 'nature of ethical applications and requirements' and the tenets of management qualitative fieldwork, my local supervisor and me discussed how I should adequately respond to these ethical aspects. For example, my local supervisor indicated the need to be as precise and explicit as possible. Thus I included details about how collective practices should be accessed in liaising with head nurses and what broad themes I intend to focus on during interviews. After completing and passing the ethical applications and requirements the ethics approval was granted after a 4month process and was based on the condition that I travelled to Saudi Arabia to undertake my fieldwork. 


\section{Noof Aldaheri, Gustavo Guzman and Heather Stewart}

Upon arrival, I received a copy of an internal memorandum on my email from the nursing administration, stating my ability to commence my qualitative fieldwork and data collection activities. I initially felt excited, until I read the given conditions "Period of data collection should not interrupt nurses' duty or compromise patient safety" and "there is no pressure for the nurse to participate in the study". My concerns arose and my excitement faded away as I realised that new constrains might be imposed.

As I was advised by my local supervisor, I took copies of the ethics approval and memorandum to the hospital academic affairs for the issuing of a hospital entry ID card, but was surprised to learn about a miscommunication that had occurred between the hospital ethics committee, the nursing administration, my local supervisor and me (the researcher). This placed me in direct encounters with the second and third layers of gatekeepers to negotiate access. The nursing administration claimed that I should have obtained permission from the academic affairs before proceeding to the nursing administration. I was also informed that I may peruse a procedure to gain academic affairs entry permission and a hospital ID card, but my request could be rejected. Consequently, the entire hospital ethics clearance and nursing administration permission become invalid. My local supervisor was surprised, as this process seemed to be new and untested.

To secure and maintain nursing-hospital settings entry, I had to engage in a series of negotiations with the third layer of gatekeepers, which included the deputy of academic affairs. During one negotiation episode, I was involved in an intense discussion about the nature of my research, informed consent procedure and core purpose of doing fieldwork with the deputy of academic affairs who has different a vocational identity from mine that is physician. The following excerpt illustrates how I initially experienced my identity as being the "suspicious Stranger" as a potential constrain to entry and how the shift in the perception of deputy of academic affairs facilitated my access to nursing settings as she had started to see me solely as a "PhD student":

"I began to relatively comprehend the possible cause underlying the occurred miscommunication. Although the deputy of academic affairs and myself both native Saudi from the same region speaking our native Arabic language, I felt in many moments as we were speaking a different language. At one point, I felt that my explanations of the research objectives and informed consent procedures were not understandable by her. For example, at many points she questioned the meanings that my descriptions convey when I described my research objectives or the informed consent procedures. Although she had not commented on the research objectives, using a cautious tone, she voiced these concerns: "Some nurses might get upset, even if they agreed to voluntarily take part they might still come to us later to complain". Then I asked her why they would complain if the right to withdraw at any point was explained to them. She remained silent, as my inquiry seemed to be unexpected. Then, I followed by clearly stating the main purpose of doing fieldwork in the nursing settings that is to fulfil the requirements of my PhD degree. She seemed to be persuaded by my purpose as she eventually assured me of the high prospect of obtaining positive outcomes. Fortunately, after two weeks, I had been granted entry to the hospital facilities by the academic affairs and was issued with my ID card."

Reflecting upon the prior excerpt indicates that negotiation nursing-hospital settings entry never ceases and its effort intensifies for those outsider researchers. This is because engagements in a series of social interactions to cross over combinations of identity dilemmas contextual factors such as being the suspicious stranger and lack of familiarity with the general principles of management research and ethnographic fieldwork methods are significantly facilitated by sharing a common vocational language. Therefore, nurses' ethnographers conducting research within the clinical area have an advantage over other researchers as they share a common language and knowledge with nursing-hospital gatekeepers (Borbasi et al., 2005; Wind, 2008), which possibly facilitate the negotiation process.

\section{Tale 2: Confronting hesitancy}

Research informants can react intensely to researchers' attempts to establish rapport in a multiplicity of protective ways (Crowley, 2007). Research informants might show hesitancy that stems from either diverse positions between the researched and researcher such as gender, race and body type (Best, 2003; Sallee \& Harris, 2011), or the level of familiarity with the research topic (Broyles, Rodriguez, Price, Bayliss \& Sevick 2011). Further, outsider researchers to the field of healthcare experienced a feeling of being burdensome 


\section{Noof Aldaheri, Gustavo Guzman and Heather Stewart}

(Sanders, Wadey, Day \& Winter 2019), and felt resistance to their presence and uncooperative attitudes (Kamarunzaman \& Selamat, 2015) without stating the root causes.

In the early days of my fieldwork journey, I felt that I was a complete outsider stranger to all nurses. I was not sure at that point whether contextual factors such as the work conditions of the hospital's wards were mirrored in nurse's attitudes as they are in a rush to finish their various assigned tasks in a timely manner or their attitudes were influenced by aspects of my identity which later became detrimental to my attempts to successfully interact and build rapport with them. This appeared from the first attempt to approach nurses as I noted in my field notes:

"This is really scary and looks perturbing", was the first impression that I formed about the general attitude of potential research informants, as I greeted a number of nurses who were sitting around the workstation, when none of them exchanged greetings or even made eye contact. The white coat that I wore did not initially give me the visibility that my local supervisor and I thought it could do. Nurses seemed to me as if they were highly disconnected from their surroundings and willing to engage only with their patients and those who were part of their nursing community. This left me wondering about the possibility of securing social acceptance and form my relation to the nursing community"

After a couple of weeks, I began to experience a shift in my identity status from a complete outsider stranger to a native outsider due to the nature of the relationships with novice native nurses. I had not experienced negative issues in socialisations and building rapport with the novice native nurses. We were native, shared the same culture and language, females from close age groups and early careers in our fields. Indeed, they saw me as a "native researcher" who should be supported as much as they can, because they "being there" experienced the involved complexities in conducting research projects in their final year of university studies.

Although I expected to encounter difficulties in establishing rapport with senior expatriate nurses, I had not entirely comprehended the possibility of confronting incessant negative reactions to my presence as an observer on the ground, and later as a recruiter in the wards. On many occasions using the "researcher" label seemed to be intimidating to them. Based on the negative reaction that I had received I used the "Ph.D. Student" label instead as part of my daily routine of introducing myself and communicating the purpose of the research. I also presented reader-friendly copies of informed consent and memos before I intended to join any collective practices or placing any sort of inquiry. In addition, to overcome the contextual factor of hectic work conditions that often take place during day shifts, I went to the wards during night shifts where more relaxed nurses are assigned fewer tasks. I adopted all of these approaches to minimise negative reactions in order to improve information accessibility.

I relatively succeeded in gaining social acceptance from several senior expatriate nurses as they started to perceive me as "student"; consequently I experienced my outsider identity as an opportunity to join collective practices and place inquires. However, negative reactions toward me ranged from ignoring greetings, avoiding socialising with me, spacious looks and hesitancy to be part of the research continued to be presented from other senior expatriate nurses. The following excerpt elucidates an encounter where I tried to recruit a senior expatriate nurse for an interview. I had set up a time and a date for an interview with a nurse clinical instructor the day before the interview was to take place, however, she abruptly hesitated the day of the interview and then eventually withdrew:

"Where are you from?" using cautious tone an expatriate nurse asked, as if she had realised a new point. "I am collecting data for my Ph.D. thesis as I mentioned to you yesterday." I then explained one more time the research purpose and showed her the ethics clearance and memo, so she could verify my identity. Unlike the recruitment day when she immediately expressed her willingness to take part in the interview without displaying any doubtable or hesitant behaviour, today with full attention she read through the memo line by line and then "I need to check with my area manager" she said. While I was waiting for her to respond, my thoughts flew as I had received a suspicious look from her deputy head nurse: she was figuring out if she has to take part in the interview to avoid implicit future negative consequences by a hospital authority or the participant is completely volunteering as I explicitly elucidated and as stated in the memo. After a few minutes, she came and said "the area manager told that it's up to me if you want to take part, but I still do not feel comfortable" then she deliberately shook 


\section{Noof Aldaheri, Gustavo Guzman and Heather Stewart}

her body as an indication of fright as if she will be a subject to negative consequences if she takes part. After a further negotiation, I just thanked her and left the ward"

This encounter left me wondering about the displayed behaviour of hesitancy and the causes of different perceptions toward me. None of the hesitant senior expatriate nurses voiced mistrust or raised any specific concerns. However, during socialisation with a native nurse, she told me that she had received advice from a senior expatriate nurse to avoid conversations with me as a way to discourage me from joining their collective practices because of concerns over reporting any heard or observed issues to the hospital higher authority. At that point, I become aware of the role of the multiplicity of my identities as being an outsider to the nursinghospital settings and a researcher in influencing some senior expatriate nurses' perceptions as they saw me as a "spy". Similarly, although Allen (2004) shared nursing identity with research informants, they did not utterly perceive her as a member of the nursing group which was evidenced in voicing concerns over making judgments about the quality of their practices which could be reported back to the administration. In addition, several nursing-hospital ethnographers experienced the intersectionality of identity dilemmas that play out at several moments in the fieldwork, which result in being differently perceived in a moment as complete insiders or as complete outsiders and occasionally both at once (de Melo et al., 2014; Ledger, 2010). Hence, I apprehended that the different perceptions of senior expatriate nurses toward me emerged from complex combinations of the interplay of the multiplicity nature of my identity such as being native, student versus researcher, outsider to the nursing - hospital setting and other contextual factors such as hectic work conditions and the degree of familiarity with the tenants of ethnography and qualitative research methods. I realised the need to actively seek an insider role to assist me in creating further social interaction opportunities to build rapport in order to enhance information access.

\section{Tale 3: Finding insider roles}

Securing formal access does not guarantee rapport with individual research informants (Cunliffe \& Alcadipani, 2016; Siwale, 2015), therefore, prior research emphasises the significance of finding a role that offers the researcher the best opportunities for building trustworthy relationships and being part of different situations (Wind, 2008). In the nursing-hospital settings, no day passed without an internal struggle in answering the question of how I could find other common ground to be perceived as part of the nursing community or at least not as a suspicious stranger. Even though novice native nurses and some groups of expatriate nurses socially accepted me as "an academic researcher" and other groups of expatriate nurses socially accepted me as "a Ph.D. student", I continually questioned my role to gain acceptance from those groups of expatriate nurses who perceived me as a "spacious stranger or spy". As a result, searching for a role that potentially assists me in reducing the physical discomfort, building rapport to gain and maintaining access to more senior expatriate nurses became my main preoccupation throughout the period of the fieldwork.

Adopting an insider role is a substantial advantage of nurse-ethnographers when conducting fieldwork in nursing-hospital contexts over other researchers. A review of several fieldwork accounts conducted by nurses' ethnographers shows that adopting a relevant role and shifting to participant-observer have been somehow considered to be an easier task supported by the fact that nurses' ethnographers and the nurses informants share a reciprocal nursing identity compared to others social researchers (Borbasi et al., 2005). On the contrary, positioning myself in relation to the nurses, particularly those senior expatriate nurses who perceived me as a "spacious stranger or spy" were an intricate and complex endeavour. In one sense, I was partially an insider as I was a native academic, having teaching experience in a national university where I worked with a culturally diverse team. In addition, being a native I am fully aware of different national regions'customs, norms, languages, history and religious beliefs. Nonetheless, in another sense, I was also an outsider, having no nursing / medical training, affiliation with the health care organisation research or strong networking relationships with the hospital's key gatekeepers.

Outsider researchers to the nursing- hospital settings reacted differently to the dilemma of fieldwork roles. Davis (2000) maintained the role of a passive observer, but she cited several occasions in the hospital setting where besides her feeling of marginalisation, she was neither able to downgrade the status of suspicion about her intentions nor cope with deliberate efforts to make her observations difficult. To overcome these access difficulties, other researchers (Sanders et al., 2019) maintained volunteer roles that assisted in earning social acceptance and building mutual relationships. Hence, guided by prior fieldworkers' experiences, I entered the hospital with an assumption that offering to volunteer in any sort of basic administrative tasks would allow me 


\section{Noof Aldaheri, Gustavo Guzman and Heather Stewart}

to integrate into the hospital wards and closely interact with nurses. Although I had expressed my willingness to the ward heads, nurse clinical instructors and nurse preceptors to volunteer in specific administration tasks, they were hesitant to designate any duties to me. As a result, I had to actively seek any other possible role that I was qualified to perform so I can demonstrate assistant initiative toward it. I found myself consciously and unconsciously getting involved in situations where communication misunderstandings between native patients and expatriate nurses took place to play the role of an Arabic-English interpreter. The following excerpt describes one of these situations:

\footnotetext{
"In such a situation when I was hanging around the nursing workstation one day, a patient left her room and came toward a senior expatriate nurse who was entering data into the computer. She asked using a regional language to give her an extra blanket. The senior expatriate nurse was staring at her and did not seem to understand what the patient was saying, although the patient repeated her request this time using sign language. At this point I jumped into the conversation and interpreted what she was trying to say then I asked the patient her room number and assured her I will bring the blanket to her. After I returned to the station, the senior expatriate nurse had thanked and engaged in casual chat with her"
}

Overall, I experienced the multiplicity of my identity in the facets of vocation, culture/nationality between senior expatriate nurses and myself sometimes as constrains and other times as opportunities. On one hand, being culturally and nationality different from expatriate nurses, I was not able to take part in many casual social opportunities to cross over largely blurred identity boundaries and negotiate access because they spoke in their own native languages which were not the hospital official languages that I can understand. On other hand, being from the field of management studies led to perceptions shift of many senior expatriate nurses who saw me initially as "spacious stranger", as I felt there was less tension associated with me joining and observing collective practices.

\section{Conclusion}

In this paper, I have explored fieldwork dilemmas that have I encountered and reflected on how they were negotiated during my fieldwork experience as an early career researcher in a nursing-hospital context in my native country of Saudi Arabia. Through employing the lens of reflexivity and the notion of "activating the hyphen" between nursing-hospital insiders, research informants and the researcher, the most uncertain fieldwork moments and their criticality in gaining and maintaining fieldwork entry and information access were selected and organised into three interrelated tales: confronting official layers of gatekeepers, confronting hesitancy and finding an insider role. This fieldwork account contributes to the management qualitative literature in multiple ways: (1) It highlights the fieldwork dilemmas involved in conducting qualitative management research within the nursing-hospital context, specifically the associated methodological dilemmas when there are fundamental differences between the researcher and researched informants; (2) As there is insufficient practical guidance on how fieldwork dilemmas can be negotiated in a nursing-hospital context for early career researchers within the current literature, it provides a practical means for reconciling contextual factors and identity dilemmas related to nursing-hospital site entry, fulfilment of ethics committee requirements, building rapport through social conversations of mutual collaboration and to cross over disagreements and identities perceptions not only the official gatekeepers and research informants, but also with other insiders; and (3) Explicit descriptions and reflections on the conditions under which data are generated in the fieldwork process through addressing the fluid and multiple formed nature of researcherresearched identities and other influential site contextual factors as part of the research methodology offers a way to contextualise the findings of management research which contribute toward enhancing the trustworthiness and richness of qualitative research findings.

\section{References}

Abdulrehman, M. S. (2017). Reflections on Native Ethnography by a Nurse Researcher. Journal of Transcultural Nursing, 28(2), 152-158. doi:10.1177/1043659615620658

Alcadipani, R., Westwood, R., \& Rosa, A. (2015). The politics of identity in organizational ethnographic research: Ethnicity and tropicalist intrusions. Human Relations, 68(1), 79-106. doi:10.1177/0018726714541161

Allbutt, H., \& Masters, H. (2010). Ethnography and the ethics of undertaking research in different mental healthcare settings. Journal of Psychiatric and Mental Health Nursing, 17(3), 210-215. doi:10.1111/j.1365-2850.2009.01493.x

Allen, D. (2004). Ethnomethodological insights into insider-outsider relationships in nursing ethnographies of healthcare settings. Nursing Inquiry, 11(1), 14-24. doi:10.1111/j.1440-1800.2004.00201.x 


\section{Noof Aldaheri, Gustavo Guzman and Heather Stewart}

Anthony, A. K., \& Danaher, W. F. (2016). Rules of the road: doing fieldwork and negotiating interactions with hesitant public figures. Qualitative Research, 16(4), 392-410. doi:10.1177/1468794115587392

Best, A. L. (2003). Doing Race in the Context of Feminist Interviewing: Constructing Whiteness Through Talk. Qualitative Inquiry, 9(6), 895-914. doi:10.1177/1077800403254891

Browne, B. C. (2013). Recording the Personal: The Benefits in Maintaining Research Diaries for Documenting the Emotional and Practical Challenges of Fieldwork in Unfamiliar Settings. International Journal of Qualitative Methods, 12(1), 420435. doi:10.1177/160940691301200121

Broyles, L. M., Rodriguez, K. L., Price, P. A., Bayliss, N. K., \& Sevick, M. A. (2011). Overcoming Barriers to the Recruitment of Nurses as Participants in Health Care Research. Qualitative Health Research, 21(12), 1705-1718. doi:10.1177/1049732311417727

Borbasi, S., Jackson, D., \& Wilkes, L. (2005). Fieldwork in nursing research: positionality, practicalities and predicaments. Journal of Advanced Nursing, 51(5), 493-501. doi:10.1111/j.1365-2648.2005.03523.x

Chesney, M. (2001). Dilemmas of Self in the Method. Qualitative Health Research, 11(1), 127-135. doi:10.1177/104973201129118876

Child, J., \& Marinova, S. (2014). The Role of Contextual Combinations in the Globalization of Chinese Firms. Management and Organization Review, 10(3), 347-371. doi:10.1111/more.12073

Chong, K. H. (2008). Coping with Conflict, Confronting Resistance: Fieldwork Emotions and Identity Management in a South Korean Evangelical Community. Qualitative Sociology, 31(4), 369-390. doi:10.1007/s11133-008-9114-0

Coffey, A. (1999). The ethnographic self: fieldwork and the representation of identity (1 ed.). London: SAGE.

Cole, C. E. (2013). Stories from the lived and living fieldwork process. Qualitative Research in Organizations and Management: An International Journal, 8(1), 50-69. doi:10.1108/17465641311327513

Cunliffe, A. L., \& Karunanayake, G. (2013). Working Within Hyphen-Spaces in Ethnographic Research: Implications for Research Identities and Practice. Organizational Research Methods, 16(3), 364-392. doi:10.1177/1094428113489353

Davis, H. (2000). The management of self: Practical and emotional implications of ethnographic work in a public hospital setting.

de Melo, L. P., de Melo, L. P., Stofel, N. S., Stofel, N. S., Gualda, D. M. R., Gualda, D. M. R., . . de Campos, E. A. (2014). Nurses' experiences of ethnographic fieldwork. Nurse researcher, 22(1), 14-19. doi:10.7748/nr.22.1.14.e1243

Feldman, M. S., Bell, J., \& Berger, M. T. (2003). Gaining access: a practical and theoretical guide for qualitative researchers. Walnut Creek, CA;Oxford;: Altamira Press.

Fine, M. (1994b). working the hypens: Reinventing self and other in qualitative research. In N. K. Denzin \& Y. S. Lincoln (Eds.), Handbook of qualitative research (pp.70-82). : Thousand Oaks, CA: Sage.

Grant, A. (2017). "I Don't Want You Sitting Next to Me": The Macro, Meso, and Micro of Gaining and Maintaining Access to Government Organizations During Ethnographic Fieldwork. International Journal of Qualitative Methods, 16(1). doi:10.1177/1609406917712394

Høyland, S., Hollund, J. G., \& Olsen, O. E. (2015). Gaining access to a research site and participants in medical and nursing research: a synthesis of accounts. Medical Education, 49(2), 224-232. doi:10.1111/medu.12622

Humphrey, C. (2007). Insider-outsider: Activating the hyphen. Action Research, 5(1), 11-26. doi:10.1177/1476750307072873

Johns, G. (2018). Advances in the treatment of context in organizational research. Annual Review of Organizational Psychology and Organizational Behavior, 5, 21-46.

Kamarunzaman, N. Z., \& Selamat, N. H. H. (2015). Gaining Access and Establishing Trust in a Fieldwork with Psychiatric Patients. Procedia - Social and Behavioral Sciences, 211, 285-291. doi:10.1016/j.sbspro.2015.11.036

Ledger, A. (2010). Exploring Multiple Identities as a Health Care Ethnographer. International Journal of Qualitative Methods, 9(3), 291-304. doi:10.1177/160940691000900304

Long, D., Hunter, C., \& van der Geest, S. (2008). When the field is a ward or a clinic: Hospital ethnography. Anthropology \& Medicine, 15(2), 71-78. doi:10.1080/13648470802121844

Moore, L., \& Savage, J. (2002). Participant observation, informed consent and ethical approval. Nurse researcher, 9(4), 5869. doi:10.7748/nr2002.07.9.4.58.c6198

Rousseau, D. M., \& Fried, Y. (2001). Location, location, location: contextualizing organizational research. Journal of Organizational Behavior, 22(1), 1-13. doi:10.1002/job.78

Sallee, M. W., \& Harris, F. (2011). Gender performance in qualitative studies of masculinities. Qualitative Research, 11(4), 409-429. doi:10.1177/1468794111404322

Sanders, P., Wadey, R., Day, M., \& Winter, S. (2019). Qualitative fieldwork in medical contexts: confessions of a neophyte researcher. Qualitative Research in Sport, Exercise and Health, 11(1), 106-118. doi:10.1080/2159676X.2017.1351390

Sergeeva, A., \& Aneeva, T. (2016). Knowledge sharing research: bringing context back in. Journal of Management Inquiry, 25(3), 240-261. doi:10.1177/1056492615618271

Sherif, B. (2001). The Ambiguity of Boundaries in the Fieldwork Experience: Establishing Rapport and Negotiating Insider/Outsider Status. Qualitative Inquiry, 7(4), 436-447. doi:10.1177/107780040100700403

Siwale, J. (2015). Why Did I Not Prepare for This? The Politics of Negotiating Fieldwork Access, Identity, and Methodology in Researching Microfinance Institutions. SAGE Open, 5(2), 215824401558756. doi:10.1177/2158244015587560

Smith, L. J. (2008). How ethical is ethical research? Recruiting marginalized, vulnerable groups into health services research. Journal of Advanced Nursing, 62(2), 248-257. doi:10.1111/j.1365-2648.2007.04567.x 


\section{Noof Aldaheri, Gustavo Guzman and Heather Stewart}

Toffoli, L., \& Rudge, T. (2006). Organizational predicaments: ethical conditions for nursing research. Journal of Advanced Nursing, 56(6), 600-606. doi:10.1111/j.1365-2648.2006.04056.x

Tracy, S. J. (2013). Qualitative research methods: collecting evidence, crafting analysis, communicating impact (Vol. 1. Aufl.;1;). Chichester, U.K: Wiley-Blackwell.

van der Geest, S., \& Finkler, K. (2004). Hospital ethnography: introduction. Social Science \& Medicine, 59(10), 1995-2001. doi:10.1016/j.socscimed.2004.03.004

Wind, G. (2008). Negotiated interactive observation: Doing fieldwork in hospital settings. Anthropology \& Medicine, 15(2), 79-89. doi:10.1080/13648470802127098 


\section{Biographies of Contributing Authors}

Noof Aldaheri is a Lecturer of MIS Business at Taif University, Saudi Arabia and a Ph.D. candidate at Griffith University, Australia. Her Doctorate's research focuses on exploration of cross-cultural knowledge sharing practices. Her main research interests are: cross-cultural management, expatriate management and HRM, knowledge management, organizational learning and workforce diversity.

Trish Alexander is a Professor Emeritus (School of IT, University of Pretoria), a Professor Extraordinarius (School of Computing, University of South Africa) and is currently in the Faculty of ICT at the Tshwane University of Technology. She prefers interpretivist research and social theory (e.g. Actor Network Theory and Activity Theory). For the latter part of her teaching career Trish has focussed on supervising senior postgraduate students.

Mukhtar Al-Hashimi, Prof, Bahraini national with 4 degrees from prestigious American higher education institutions. Started academic career as Assistant Professor while medical informatics advisor for Bahrain Ministry of Defense medical services. Developed nationally recognized medical Information System for Bahraini Defense force's medical services. Publications and interests pertain to Information Systems Development, Design, and Implementation. Currently, Vice President, Academic Affairs of Ahlia University, Bahrain.

Abdalmuttaleb M.A. Musleh Al-Sartawi Chairperson of accounting and economics department, Editor-in-Chief of the International Journal of Electronic Banking (IJEBank). He received his PhD in Accounting, from UBFS. He has chaired as well as served as a member in various editorial boards and technical committees in international refereed journals and conferences.

Manuel Au-Yong-Oliveira has a PhD in Industrial Engineering and Management from FEUP (University of Porto). Manuel is an Assistant Professor at the University of Aveiro, and a researcher affiliated to GOVCOPP. At present, Manuel is the Director of the Master's degree in Management at the University of Aveiro, in Portugal. Manuel is also a member of the Executive Committee of his department - DEGEIT - University of Aveiro. Manuel has close to 200 academic publications.

Levente Bakos, is a PhD student in Management at Lucian Blaga University of Sibiu and teacher at the Hungarian Sapientia University from Transylvania, Romania. He is mechanical engineer and economist, with scholar and practitioner experience in industrial management and public administration. His research interests are: Holonic Manufacturing Systems, Risk Management, CSR, Public Relations in economy.

Amina Buallay is Head of Administration and Financial Services in the Ministry of Education, Bahrain. Currently, she is a PhD scholar at Brunel University, London. She holds a Master's degree in Business Administration from Ahlia University, and a Post Graduate Diploma in Business Education and Bachelor's degree in Accounting from University of Bahrain. She conducts research in the area of Intellectual Capital, Corporate Governance, and Sustainability Reporting.

Portia Buthelezi is a Senior Lecturer at the University of South Africa. College of Science Engineering and Technology in the School of Computing-Computer Science Department. Her research interests are in the field of research methods, mobile bullying, information security, focusing on user interactions and awareness of the security aspects within the information systems that they use (Cyber security awareness).

Chris William Callaghan is a Professor of Management in the School of Economic and Business Sciences of the University of the Witwatersrand, Johannesburg, South Africa. He is founding director of the Knowledge and Information Economics/Human Resources Research Agency (KIEHRA).

D. A. L Coldwell, Professor B.Sc. (Soc) London, B.A. (Econ), M.A., D. Litt et Phil, FCIPD, FRSA is a Professor of Management at the School of Economic and Management Sciences, University of the Witwatersrand. A National Research Foundation (NRF) accredited researcher, he has produced books and written articles in premier national and international journals. 
Reproduced with permission of copyright owner. Further reproduction prohibited without permission. 